Berendzen, R. 1968, The Career Development and Education of Astronomers in the United States, thesis Harvard University.

Education of Astronomers $\quad 1969$, Q. J. R. astr. Soc., 10, 21.

McNally, D. $\quad 1968$, Education for Astronomy, Careers Bulletin autumn 1968, p. 6 (Central Youth Employment Executive, London).

Miller, F. D. $\quad 1969$, How to Become an Astronomer, Sky Publishing Corp., Cambridge, Mass.

Ross, S. S. $\quad 1969$, Conference on Laboratory Exercises, Sky Telesc., 38, no. 5, 304.

Taylor, R. J. $\quad 1969$, Q. J. R. astr. Soc., 10, 44.

Schalén, C. 1965, Att Studera Astronomi, Svenska Bokförlaget (Scandinavian Univer. Books).

Wentzel, D. G. 1969, Science Education: Case for Astronomy, Astronomy Program, Univ. of Maryland, College Park, Md. 20742, U.S.A.

Wentzel, D. G., Smith, E. v. P. 1969, Informal Resource Letter on Astronomy Laboratory Exercises, Astronomy Program, University of Maryland, College Park, Md. 20742, U.S.A.

\title{
THE INTERNATIONAL SCHOOLS FOR YOUNG ASTRONOMERS
}

With the financial support of UNESCO the IAU organized three International Schools for Young Astronomers (ISYA) so far, the first in Manchester, United Kingdom (1967), the second in Arcetri, Italy (1968), and the third in Hyderabad, India (1969). The organization was in the hands of Dr. J. Kleczek, secretary of the ISYA. The report on the Manchester School is published in the IAU Trans. XIIIB.

The Arcetri ISYA was devoted to modern Solar Physics. Ten students from seven different countries attended the school (Bolivia:1, Brazil:2, Czechoslovakia:3, Hungary:1, Poland:1, Sweden :1, and Turkey :1). The Arcetri astronomers were in charge of most of the 70 hours lectures, the 142 hours of practical training and the series of seminars held during the school of $81 / 2$ weeks duration. In addition, two European professors were invited to give a couple of lectures. The school was financed in part by UNESCO and in part by the Arcetri Observatory and the Italian Government. M. Rigutti prepared a detailed report on the basis of (a) his and his colleagues' experiences during the ISYA, and (b) the answers to a questionnaire he had mailed after the end of the school to all attending students. Prof. Rigutti's excellent report is a very useful document and should be used as guideline for the planning of future ISYA.

The subject of the ISYA at the Osmania University in Hyderabad was Stellar Astronomy and Astrophysics. It was attended by 23 students from 5 Eastern countries (Ceylon :2, China :1, India, 18, Japan :1, New Zealand :1). During 8 weeks the students attended a total of 200 hours of lectures and practical training which were given by 7 invited professors from abroad and 6 professors from various Indian Universities and the astronomical staff of the Hyderabad Observatory. The school was financed in part by UNESCO, in part by the New Delhi University Grant Commission, and in part by the IAU.

The following is a brief synthesis of the results of the three ISYA as reported by J. Kleczek:

"In general, both the lecturers and the young astronomers considered the ISYA a success. They appreciated the 'home-like' and friendly atmosphere. To many young astronomers the school was of great help in formulating and preparing their future research programs. This is especially true about young astronomers from countries where the possibilities of education and research in astronomy are not very advanced. The contacts between the young astronomers and the lecturers, and among the young astronomers themselves do not end with the termination of the school. These post-school relations are an important result of our schools."

"In organizing the schools in Manchester and Arcetri young astronomers from various countries were brought to an Observatory to work with local lecturers and instruments. At Hyderabad, on the contrary, a new scheme was tried, namely to bring foreign lecturers and experienced research workers to an Observatory which, with newly acquired telescopes, is developing its astronomical research programs. The scheme was effective and it has the advantage that the experienced astronomers can help the host Institute to plan future research programs. For example, a special seminar was arranged at Hyderabad dealing with the exploitation of medium-size telescopes. (In the nearest 
future, the three principal Indian Observatories will begin to work with new telescopes of about one meter diameter)."

"Participants of all three schools complained that the instruction was too concentrated and that they had difficulties assimilating the new material. We are facing a dilemma: either to limit the lectures or to have schools of three months' duration. To reduce the lectures would mean to cripple the whole program; nothing unimportant is taught. Prolongation of the school, on the other hand, would require the reduction of the number of participants; we are limited by the available finances. For the moment, the young astronomers must try to finish assimilating the new material at their home institutes. They receive mimeotyped texts of the lectures for this purpose."

"It is the Secretary's opinion, that the ISYA brings great benefit to young astronomers from astronomically developing countries. Preference should be given to them, while a small number of participants from astronomically more developed countries should be admitted too. We had a few very good young astronomers who, for quite different reasons, had no possibility to continue their studies and research at home. The ISYA Secretary is grateful to the Commission members for not being indifferent to such cases."

The IAU Executive Committee has re-appointed Dr J. Kleczek as Secretary of the ISYA for another period of three years.

Dr J. Kleczek hopes to organize the 1970 ISYA in Argentina for the benefit of the Latin American young astronomers, and for the 1971 ISYA he is considering an African country.

In the name of the Commission and of all students attending the ISYA, the Commission President wishes to thank the UNESCO, the IAU, and the host countries for their generous financial support without which our schools would not have been feasible. Our greatest appreciation goes to Dr J. Kleczek for all his efforts and the efficient organization of the ISYA, and to the lecturers and astronomers of the host Observatories for their kind collaboration. They all contributed to make our ISYA so successful.

\section{COLLABORATION WITH INTERNATIONAL COMMISSIONS ON SCIENCE TEACHING}

In 1968 the CIES (Commission Internationale de l'Enseignement des Sciences) - an inter-union commission of ICSU organized a congress which was held from September 11 to 19 at the international center in Droujba near Varna (Bulgaria). The IAU was represented by Prof. M. Minnaert replacing Prof. E. A. Müller who was unable to attend. The proceedings of this congress are published by the Secretary of the CIES, Prof. P. Fleury (3, Boulevard Pasteur, Paris XV). The following two papers related to astronomy were presented:

M. G. J. Minnaert: The Integration of Astronomy into a Course of Physics

E. Schatzman: Place de l'astronomie par rapport au autres sciences.

Prof. $M$. Minnaert's report on the congress is reproduced here in abbreviated form:

"The general tendency of the congress was to have at the elementary school an integrated teaching by one and the same teacher, including mathematics as well as sciences. In the first cycle of the secondary school the sciences of nature should be integrated, while mathematics ought to have a separate teaching. In the second cycle the same could apply to pupils not wishing to follow later a career in sciences. For the others, integration seemed not desirable, except perhaps between physics and chemistry; but close coordination between the different disciplines was expected. The eastern countries and Denmark were least inclined to the integration which different groups in the U.S.A., Australia, and Great Britain propagated. - It was most interesting to see the display of excellent textbooks written for integrated courses in sciences for secondary schools. The subjects treated are essentially: air, water, the forest, the farm, food, the seasons, motion, light, energy, etc. The connection with life at large was most enjoyable."

"The subject of integration in the teaching of the different sciences and of mathematics is, of course, of considerable importance for the teaching of astronomy. Here is an opportunity to have our science taught to a great part or to almost all of the pupils. On the other hand, there might be the danger that it would lose its proper value, especially if it were taught by a teacher who is not 
sufficiently prepared for this part of his task. - In the higher classes there is the problem of whether astronomy should be integrated with physics or with the earth-sciences (geology, meteorology, etc.). In the present situation I prefer the combination with physics, because as it is now, the teacher of earth sciences will not have been educated in modern astronomy; moreover, earth sciences are only taught in some countries."

"In a plenary session I stressed the great significance of astronomy in secondary education. Later, in one of the working groups, I showed in a more extensive and somewhat more technical manner how astronomy may be integrated with physics, but what precautions have to be taken in this case in order to save the proper value of astronomy as such. - At the end of the congress a concluding report was read and approved to which were added 15 statements, summarizing the main recommendations of the congress to pedagogical authorities and departments. In the final report the following paragraph appears:

\section{Astronomie et physique}

L'astronomie fait emploi des mathématiques et de la mécanique, mais elle participe surtout de la physique sous toutes ses formes. Elle a en outre des points communs avec les sciences de la terre et avec la chimie. Des notions d'astronomie moderne, comprenant spécialement l'astrophysique, sont indispensables dans l'enseignement secondaire. L'astronomie mérite d'être enseignée comme une discipline autonome; elle peut être aussi intégrée dans l'enseignement de la physique. Dans ce dernier cas il sera nécessaire, à fin des cours, de récapituler en quelques leçons les notions acquises, en les regroupant de manière à construire un modèle synthétique de l'univers."

In the concluding statements, issued by the congress and which will be diffused on a much larger scale, Prof. Minnaert succeeded in having the following statement printed:

"The physics teacher should be responsible for teaching mechanics as well as astronomy; the introduction of some notions of astronomy in secondary schools is desirable."

On December 12 and 13, 1969, E. A. Müller, as the President of the Commission 46, was invited by ICSU to Paris to attend the first meeting of a newly formed international Committee on Science Teaching (CST) under the chairmanship of Dr M. Matyas of Czechoslovakia. Participants were some representatives of ICSU and of UNESCO, and the presidents of the Teaching Commissions of the various Scientific Unions who reported on the activities of their Teaching Commissions. The topics discussed for the future programs of the CST were the following: modernisation and coordination of science teaching; integration of sciences; cooperation with UNESCO; exchange of information and teaching experiences among the various Scientific Unions; continuous education of the science teachers; guide-lines for improving the science teaching in developing and developed countries; social responsibilities of scientists. A second meeting of the CST is scheduled for the second part of April 1970.

\section{REPORTS ON NATIONAL ACTIVITIES IN ASTRONOMY EDUCATION}

The Commission members were invited to submit a report on new developments in the teaching of astronomy in their own countries. $75 \%$ of the members sent a report, and some of the reports are very interesting and detailed and may interest other members of the Commission. Due to lack of space in the IAU Draft Report only a brief summary of the trends in the astronomy teaching activities can be presented here. The individual complete reports will be reproduced in mimeographed form and distributed to all Commission members. It should be added, that any astronomer interested in the detailed report of a particular country may order a copy either through the Commission member representative of that country, or through the Commission President.

\section{Astronomy education in elementary and secondary schools}

Members of the following countries reported that astronomy has been - or is in the process of being - introduced in Schools: Argentina, Belgium, Bulgaria, Canada, Czechoslovakia, Denmark, German Dem. Rep., German Fed. Rep., Japan, The Netherlands, New Zealand, Poland, Rouma- 
nia, Switzerland, United Kingdom, U.S.S.R., and U.S.A. The level of astronomy teaching is quite different in the different countries. In the elementary school level astronomy is usually integrated in the earth sciences. At the secondary school level some notions of astronomy are given in either mathematics or physics courses, and in only a few places astronomy is taught as a separate course (usually optional) in either one of the last two years of secondary school. Often the teaching of astronomy in schools does not go much beyond the Earth-Moon and the Earth-Sun system. The main problem of school astronomy is that the teachers themselves are not well prepared, they know very little about modern astronomy. In order to overcome this difficulty, astronomy courses for teachers are being organized in several countries (e.g.: Argentina, German Fed. Rep., The Netherlands, Poland, Switzerland) during which the school teachers get acquainted with modern astronomy and astrophysics through lectures and practical training on school telescopes. Didactic books and guide-lines in astronomy for school teachers would be of very great help. In a few countries such teaching aids have been prepared, but much more should be done about this.

\section{General astronomy education at the university level}

In several countries new programs have been or are being developed for the introductory courses in astronomy and astrophysics. These courses are given to science students who may or may not become astronomers later on. A number of these students may eventually go into secondary school and/or college level teaching and, thus, will be better prepared for the astronomy teaching in schools than the teachers have been so far. Also, in some countries (e.g.: France, German Fed. Rep. and others) one tries to coordinate and unify the introductory and basic courses of astronomy and astrophysics given at various universities.

\section{Education of astronomers}

Everyone agrees that the education of astronomers starts with a good education in physics and mathematics. The training for becoming an astronomer then requires a number of basic astronomy and astrophysics lectures and seminars, and much practical training and research work. Obviously, the education of astronomers very much depends on the facilities available in individual countries and universities. In recent years many universities have reconsidered and modernised their programs for astronomy studies. Universities which only recently have started an astronomical program may make use of the facilities of an observatory of another university in the same country or in a neighbouring country. How in individual countries the education of astronomers has been improved or recently introduced can be read in the detailed report of the national activities in astronomy education.

\section{Education in astronomy of the general public}

Various Commission members report that astronomy education of the general public is done (a) by regular public lectures given by the astronomers themselves or by amateur astronomers, (b) by visits to planetaria, (c) by series of radio or television transmissions on astronomy, and (d) by a number of popular books which have appeared on the market in recent years. 